\title{
Speech Production of Trilingual Children: A Study on Their Transfers in Terms of Content and Function Words and the Effect of Their L1
}

\author{
Fotini Anastassiou ${ }^{1} \&$ Georgia Andreou ${ }^{2}$ \\ ${ }^{1}$ Bilingual Education Laboratory, University of Thessaly, Greece/ Hellenic Open University, Greece \\ ${ }^{2}$ Department of Special Education-Bilingual Education Laboratory, University of Thessaly, Greece/ Hellenic \\ Open University, Greece \\ Correspondence: Fotini Anastassiou, Bilingual Education Laboratory, University of Thessaly, Greece/ Hellenic \\ Open University, Greece. E-mail: fanastassiou@gmail.com
}

Received: January 7, 2017 Accepted: July 11, 2017 Online Published: September 15, 2017

doi:10.5539/ijel.v7n6p30 URL: http://doi.org/10.5539/ijel.v7n6p30

\begin{abstract}
The present study investigated the speech production of trilingual children whose L1 was either Greek or Albanian and their L3 was English. Since this specific combination of languages has not been widely studied in current literature this study can contribute to our knowledge and the teaching of these children. Moreover, research into transfers from content and function words could help us comprehend the different roles word classes have in trilingual speakers since Paradis (2009) has suggested that the tendency to transfer function words from L2, rather than from L1, into L3 supports the idea that content words and function words have the same status in an L2 but not in L1. Also, although content words are often transferred from both L1 and L2 into L3, studies have indicated that function words are mainly transferred from the L2 and not from the L1 (Ringbom, 1987; Sjögren, 2000; Stedje, 1977). The aim of this study was to find out the source language of our participants' transfers, whether there would be any influence of our speakers' L1 or L2 on Content and Function words, as well as whether cross-linguistic influence had any effect on Content and Function words, following Cenoz (2001).The participants of our study were asked to narrate a picture story in their third language and the main source of their transfers was surveyed. Also, the ratio of Content to Function words and the effect of the children's L1 was investigated since former research showed function words are mainly transferred from the L2 and not from the L1. The results of this study showed that the main source of transfer was Greek (whether as an L1 or an L2) and that the children's transfers were mainly from content words. Finally, the ratio of Greek content/ function words was found to be greater for those children whose L1 is Greek compared to the children whose L1 is Albanian.
\end{abstract}

Keywords: multilingual children, cross-linguistic influence, speech production, transfers, parts of speech, content words, function words

\section{Introduction}

Multilinguals may use several languages due to their different social, cultural and economic backgrounds and field of using their specific languages. They might live in a multilingual community, or bilingual communities, or they might be in contact with several monolingual communities during their everyday routines or social life. Their proficiency in each of their languages is possible to differ, and might change over time (Herdina \& Jessner, 2002). The multilinguals' languages can have distinguished roles and functions, they may use them separately or code switch and code mix and last but not least they are still seen as multilinguals even if they use three or even six languages.

The ability of a person to speak more than one language can occur under a variety of conditions. Edwards (1994, p. 39) states that "in most instances, multilingualism arises, and is maintained, through contact and necessity". Thus, the emergence of two or sometimes three languages can exist when in each language there is both a source of input and the necessity for communication. In Greece, for example, there has been a growing tendency on behalf of Albanian heritage speakers to use this language less compared to Greek.

Cases of trilingualism can be categorized into four interrelated variables: (a) the age of the speaker when he made his first important contact with the language, (b) the input they receive (type, modality and quantity) (c) 
the level of proficiency in each language and (d) the order that the languages where obtained. It is not compulsory that the previously mentioned variables should be independent, although this may also be the case. For example, the time the speaker made his first contact with the specific languages could have a close correlation with the input, i.e., younger speakers could be expected to have a more "naturalistic way of acquiring their language" than older speakers. Apart from that, in the involvement of three languages, there are many inherent variations in each learner, within each variable, as in the occasion of all cases of language acquisition.

It has to be clarified that the manifestation of the previously mentioned variables leads in various possibilities that would all outline different types of trilingual speakers, and such situations can be further divided according to the age of the speaker, the type and amount of input they receive and the proficiency in each language, considering also the order of acquisition. According to Hoffman (2001, p. 3) the following classification can be suggested:

a) Trilingual children who grew up having adapted two home languages different from the one spoken in the community.

b) Trilingual children grown up in a bilingual community and their home language (either spoken by one or both of their parents) is different from the language spoken in the community.

c) Third language learners, that is, bilinguals who obtain a third language in the context of school education.

d) Bilingual individuals who have turned into trilinguals through immigration.

e) Individuals that belong to trilingual communities.

The present research focuses on children who have acquired their L1 and L2 and are currently learning their L3 within school context (Hoffmann's third category). Specifically, this research surveys the language interaction of children who come from an Albanian background and they were born and raised in Greece. They have learnt Albanian from their family, Greek from their family and their social environment and they have also received formal instruction in Greek at school. Also, they are currently being taught English (L3) at school. It should be noted that their L1 may be either Greek or Albanian according to the statements of our participants.

\section{Literature Review}

\subsection{Word class and Transfers}

Within language transfer and particularly on the lexis level we can distinguish the one happening from content and the one from function words. According to Murphy (2003) these transfers seem to be largely related to control and attention. She cites Faerch \& Kasper (1986) who distinguished the transfer of content words as a conscious strategy in the speaker's attempt to fill a lexical gap. They also stated that content words were usually found after a pause. Function words were usually found to be unintentional transfers of frequently used L1 words.

The frequency which certain linguistic features appear in the L1 seems to determine its transfer during L2 production (Murphy, 2003). According to Kellerman (1983) in terms of the perception of the speaker on a certain linguistic item and its frequency of appearance in his/her lexicon it may be considered from a psychological point of view as more "problematic" with regard to its use and its function. Therefore, such an item or feature has fewer possibilities to appear during L2 production.

According to Poulisse \& Bongaerts (1994) the frequency of the use of function words in one's L1 determines the degree of their appearance in his/her L2 too. They have also shown that L1 function words are rarely phonologically or morphologically adapted to their L2 and they attributed this finding to frequency as well as the degree of attention. Williams \& Hammarberg (1998, p. 323) maintained that "provided the factors of proficiency, typology, and recency are at a sufficient level, L2s appear more likely to be activated than the L1 as supplier language during the early stages of L3 acquisition". Ringbom $(1986,2001)$ has suggested that transfer during L2 acquisition is mainly short, complete and it involves non adapted L1 function words. Also, lexical transfer during L3 production has shown a tendency to employ more function than content words. Hammarberg (2001) also found that there was an L2 transfer for the unconscious switches his subject made and they were mostly short function words, e.g., mit (with). Cenoz (2001) whose study we followed, has found that her participants had transferred almost seven times more function words from Spanish compared to Basque and she justified this finding by means of the typological proximity of Spanish to the target language (English) of the narration.

However, Hoffmann \& Stavans (2007) investigated trilingual children from their infancy to their early childhood. The study involved two periods of the children's speech recordings, one at an early age and a second after three years that the participants had grown up more. During the first period of the recordings the children borrowed 
more often from content words, namely nouns and verbs. This finding was duplicated with the second session of the recording and the children that were now older borrowed from content words again; however the proportions of the lexical transfers were different from the first session because the children used fewer nouns or they would be morphosyntactically violated compared to the verbs.

In our study we have focused on transfer and particularly on the lexical level and we aimed to investigate whether cross-linguistic influence will affect our participants' use of content and function words. In view of the relatively few data currently available from similar studies and the fact that the particular combination of languages has not been investigated before, especially when it comes to speech production and the Content and Function words analogy, it is believed that it will be of interest and that it will contribute to so far research on this field.

\section{Methodology}

The methodology chosen for this study was largely based on a research conducted by Cenoz (2001). We used the picture story "A boy, a dog and a frog" by Mercer Mayer (1967) in order to elicit the children's free narration. Before the narration the participants were asked to fill in a questionnaire which aimed at obtaining information regarding their language biography history. This information was planned to be seen together with the data obtained by the children's narrations.

The children were asked to narrate the picture story in their third language, English, the one that they were being taught as a foreign language at school. Then their narrations were transcribed and instances of code switching and code mixing were identified and analyzed in order to determine the main source of transfer. Finally, the ratio of each part of speech from each language used within the produced "texts" was analyzed and the factor of the children's L1 as a determinant of these transfers was investigated.

\subsection{Participants}

There were 49 children that took part in this study, they all came from Albanian immigrant families and they were born and raised in Greece. Their parents had come to Greece from Albania about twenty years ago. The participants were bilingual (Albanian and Greek) and they were all learning their third language (English) within school context. It is to be noted that none of our participants was taught Albanian and thus their knowledge of their heritage language was only based on their parents' input. At this point we need to clarify that not all children had stated that they had the same L1; there were 30 children (61\%) that stated their L1 was Greek and 19 children (39\%) that stated their L1 was Albanian.

The participants were between the age of nine and twelve years old and they were attending public primary schools with a monolingual curriculum. English is to these children a third language, although for the majority of their classmates English is the second language learnt with a foreign language methodology. Therefore, our participants were more experienced language learning wise compared to their classmates, since they have been learning their third consecutive language.

This study is discussing children who are in the process of acquiring their third language, and are clearly not equally competent in all of them (see Bialystock, 2001, for a discussion of how bilingual people need not to be equally proficient in their two languages.) They are referred to as being trilingual because they are, for the time being at least, comfortable with their trilingualism, and appear to be able to communicate in each language, at least to a certain standard.

\subsection{Procedure}

After the first step of the questionnaire process was done the children were told that they were going to narrate a story according to the picture book that they were shown. They were told that every child can narrate as he/she likes and that the researcher was interested in listening to the same story told by every child in their own way. This introduction was tested with the first five children of the research and it was seen that it made them feel more at ease with the whole procedure.

\subsection{The Transcriptions}

The narration of each child was transcribed and utterance boundary decisions were based on intonation contours and pauses according to the CHILDES project directions (MacWhinney, 2000). In order to achieve an accurate transcription the children that used Albanian during their narrations were identified at the time of interview, their audio file was archived in a specific folder and they were all given to an Albanian native speaker to transcribe them. In order to make sure that these transcriptions would be done in a unified manner with the rest of them, the researcher was present during the task; she cooperated with the interpreter and supervised each one of the 
produced "texts". Also, the researcher filled in the Greek and English words during these specific transcriptions.

\subsection{Texts Analysis}

Each one of the forty nine texts that were finally chosen to be part of the study was analyzed in terms of part of speech in each language used and the instances of code switching and code mixing were identified. The target language of the narration was English; therefore code switches were identified as whole utterances in Greek or Albanian. Code mixes were identified as those utterances that Greek and/or Albanian and/or English were used in the same utterance, in accordance to Muysken (2000).

For each utterance and for each one of the three languages in question the parts of speech were divided in two categories: Content and Function words, as in Cenoz (2001). Content words include: nouns, verbs, adjectives, adverbs and numerals. Function words include: prepositions, conjunctions, determiners and pronouns. Each one of the words of each utterance was appointed to the relevant part of speech of one of the three languages that was used. Then, the parts of speech of each language were grouped in Content and Function words.

\subsection{Research Questions}

We aimed to investigate the following questions:

Which will be the main source of transfer (L1 or L2) while the children narrate in their L3?

What will be the participation of content and function words of each one of the three languages?

Will cross linguistic influence affect content and function words and what will the impact of the children's L1 be on them?

\section{Results}

First we investigated the main source of transfer of our participants while narrating in their L3. In a total of 49 texts, there were 875 utterances produced. The total of the texts produced (corpus) consisted of 8993 words and usage per language is as follows: $76 \%$ of the words produced were English (the target language of the narration), $23 \%$ of them were Greek and 1\% of them were Albanian. Then we looked into code mixes (i.e., utterances that contained two or more languages) and the usage of languages therein was as follows: the English words were $58,8 \%$ of them, the Greek words were $38,7 \%$ of them and the Albanian words were $2,6 \%$.

Clearly, the main source of transfer during the children's narrations in their L3 was Greek. In fact this was found to be the case for the children that had stated that their L1 was Greek as well as those that had stated that their L1 was Albanian.

Since we looked into the matter of Greek transfers both comparatively and separately we did confirm this finding. In fact, Greek as an L1 was found to be transferred more in comparison to Albanian as an L1 and Greek as an L2 was found to be transferred more in comparison to Albanian as an L2. The Greek language which is the official language of the country as well as the medium of every day communication has dominated these children's heritage language. These children's parents have not insisted on using Albanian at home, since they have perceived it as a less "useful" language. This was due to their immigrant mentality. Also, its "lower" social status has been rather crucial towards the language shift observed with this immigrant community in Greece. Children have not been using Albanian with their families in order to achieve a more "native" identity for themselves. Besides, Gogonas (2009) has reported the denial of children to speak Albanian at home when their parents addressed them in their heritage language. With this finding in mind we proceeded to look into the second question of this study, that is, the transfers of Content and Function words.

As far as the ratio of the Content and Function words is concerned and the effect of the children's L1 on these transfers, we first wanted to see what the percentages of the content and function words was in each one of the three languages in our entire corpus. We found out that as far as the English language is concerned, content words were more than the function ones, which measured to $54 \%$ and $46 \%$ respectively. The Albanian content words were again more compared to the function ones, and in fact the majority of the Albanian words were Content ones (68\%). The Greek content words were again more than the function ones, although their difference was not so great ( $59 \%$ to $41 \%$ respectively). As far as the total words found in our corpus, our results showed that the total content words outperformed the total function words and their difference was considerable (55\% to $45 \%$ respectively).

We then proceeded to see the distribution of content and function words within the code mixed sentences. As seen in figure 5.41 below, we immediately observe that Content and Function words presented the same proportion both in the total of the texts and at the same time in the code mixed sentences that contained English. The code mixed sentences that contained Albanian showed a different distribution since the percentage of the 
content words was higher compared to that of the Function words (67\% and $33 \%$ respectively). The same differentiation was found with code mixes that contained Greek since the percentage of Content words was greater than that of the Function words (61\% and 39\% respectively). This finding shows us that the analogy of Content and Function words seems to remain the same in the texts produced. More specifically, the parts of speech of each language retained the same "space" in the children's narrations in the code mixed sentences too.

When we had code mixed sentences and Albanian language was used in it, Content words were more than Function words. This outperformance of Content words compared to Function words was found in such a greater ratio only with Albanian and Greek (2 and 1,54 respectively) which are highly inflected languages - although the children borrowed more Content words from Albanian than from Greek.

Also, English had a Content/ Function words ratio close to 1, which means that their usage was almost the same. Furthermore, the same ratio, close to 1, was found in the Total of Content and Function words produced, in all of the texts, in the total of code switches and in the total of the code mixes produced (Figure 1 below).

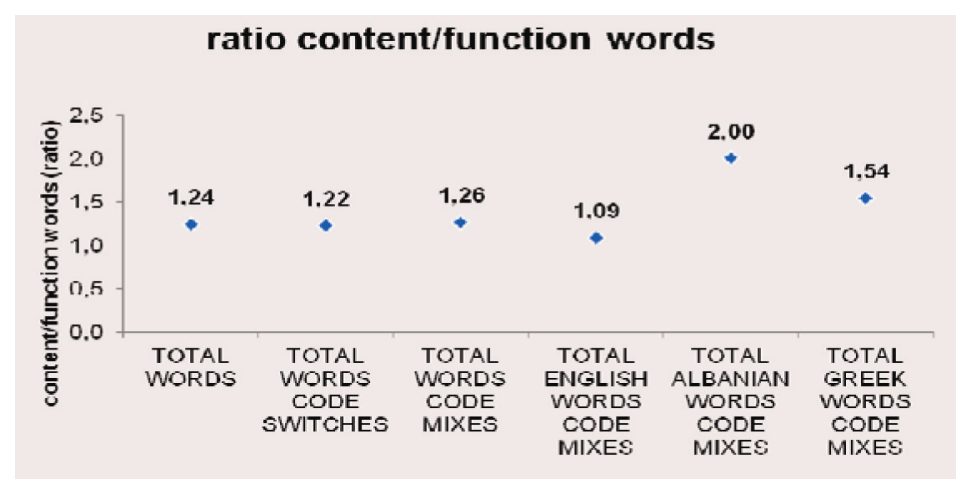

Figure 1. The ratio of content and function words in code switches, code mixes and the entire corpus.

For those children that narrated in their L3 and they only transferred from Greek we calculated their ratio in English-Greek code mixes by distinguishing them in Greek and English words. Therefore, two new variables were created for each one of the children:

a) "Ratio of Greek Content/ Function words": the ratio of Greek content and function words in English-Greek code mixed sentences.

b) "Ratio of English Content/ Function words": the ratio of English content and function words in English-Greek code mixed sentences.

We investigated whether the children's L1 affected the ratio of English Content/ Function words. This question was tested via independent t-test. It was found that the children's L1 did not have an effect on the ratio of English Content/ Function words: $\mathrm{t}(34)=0.3, \mathrm{p}=0.976$.

Moreover, we went on to see whether the children's L1 affected their ratio of Greek Content/ Function words. This question was tested via independent t-test. The children's L1 had a significant effect on the ratio of the Greek Content/ Function words: $\mathrm{t}(24.625)=2.136, \mathrm{p}<0.05$.

Finally, the ratio of Greek Content/Function words was found to be greater for those children whose L1 is Greek $(M=2.8, S D=1.87)$ compared to the children whose L1 is Albanian $(M=1.8, S D=0.78)$, (see tables 1 and 2 below).

Table 1. Descriptive statistics of the ratio of the Greek content to function words within the category of L1

\begin{tabular}{lllll}
\hline & L1 & Number of children & Mean & Std. Deviation \\
\hline Ratio of Greek Content/Function words & Albanian & 17 & 1.8 & 0.78 \\
& Greek & 19 & 2.8 & 1.87 \\
\hline
\end{tabular}


Table 2. Descriptive statistics of the ratio of the English content to function words within the category of L1

\begin{tabular}{lllll}
\hline & L1 & Number of children & Mean & Std. Deviation \\
\hline Ratio of English Content/Function words & Albanian & 17 & 1.2 & 0.57 \\
& Greek & 19 & 1.2 & 0.49 \\
\hline
\end{tabular}

\section{Discussion of Results}

Content words were used more compared to Function words; however, there was a higher tendency for the usage of Content words of Albanian and Greek (the participants' L1 and/ or L2). Also, since L3 (the target language) is used more in the entire corpus $(75,5 \%)$, the English Content and Function words were used almost in the same degree and thus the ratio is close to 1 .

This was confirmed in the total of the texts produced as well as in each one of the three languages in question. A higher ratio of Content than Function words was found in Albanian and in Greek, which are both highly inflected languages. The findings of this study are in line with Hoffmann \& Stavans (2007) who found a prevalence of Content words compared to Function words. Also, these results are in line with Cenoz (2001) who found that children used more content than function words. She also noted that there was a prevalence of Content words from one of the languages of her participants (Spanish) while narrating in their L3, like we found with Albanian Content words. Spanish and Basque are both official languages in the Basque country. In our case, Albanian is a heritage language of this particular immigrant group and does not have an official status. As mentioned before none of our participants was taught Albanian and thus their knowledge of their heritage language was only based on their parents' input.

Poulisse \& Bongaerts (1994) that studied bilinguals found that their English language learners transferred more function words than content words from their L1 (Dutch) which is a finding opposite to our study, Cenoz's (2001) as well as Hoffmann \& Stavans' (2007). Ringbom $(1986,2001)$ has suggested that transfer during L2 acquisition is mainly short, complete and it involves non adapted L1 function words. However, the findings on L2 speech production by Poulisse \& Bongaerts (1994) do not seem to coincide with those studies that concern L3 speech production. According to Murphy (2003, p. 15) "when function words are transferred in an L3 utterance, they are overwhelmingly supplied by the L2 even though the L1 function words must still have higher activation if the L1 is the language of highest proficiency. It appears that during L3 production, particularly in the early stages of acquisition, L2 status overrides the frequency effect associated with high proficiency".

Our findings though showed that the children whose L1 was Greek transferred more Greek content and function words compared to the children whose L1 was Albanian and this has also yielded a statistically significant result. Also, the ratio of Greek Content/ Function words was greater for those children whose L1 is Greek (compared to the children whose L1 is Albanian). Therefore, it seems that our participants' L1 was a significant factor as far as the degree of use of Content words is concerned. Especially, the fact that the L1 Greek speakers produced more Content words from Greek than from Albanian shows that the L2 status or the "foreign language effect" (Hammarberg, 2001) is not a factor that influenced this transfer. The first language of our speakers along with the greater frequency of use of Greek (since it the mean of everyday communication) and their higher competence in Greek too, show that what Murphy (2003) suggested does not seem to be the case with all of our participants.

Moreover, the factor of psychotypology seems to have played its role since more transfers were done from Greek Content words than Albanian Content words. The fact that Greek and English must have been perceived by our participants as closer typologically speaking seems to be in line with Cenoz (2001) who found that her participants had transferred almost seven times more function words from Spanish compared to Basque and she justified this finding by means of their typological proximity to the target language. Basque is not typologically related to English, compared to Spanish; however, the languages involved in our study belong to the Indo-European language family although Greek and Albanian are isolate languages.

However, the loans and the historical relations between Greek and English are quite closer compared to those between Albanian and English. It might then be the case that our participants had perceived this proximity and they transferred more Content words from Greek while speaking in English. Another factor that could be suggested to have played its own role might be that of the higher social status of Greek. Since the immigrant mentality of our participants seems to have influenced them in favour of the official language (Greek) of the country they live in, it might have been the case that they mostly drew items every time they needed to from Greek and not from Albanian. Further research on the production of trilingual children with the same combination of languages that our study dealt with would provide us with more information regarding the degree 
of use of Content and Function words from each one of them. Finally, as De Angelis (2007, p. 43) rightly points out "more of a puzzling issue relates to how learners make use of content and function words from their non-native languages". Since there have not been many studies on trilingual children's transfers with regard to Content and Function words more research on this issue with different combinations of languages could shed light in this matter too.

\section{References}

Bardel, C., \& Falk, Y. (2012). The L2 status factor and the declarative/procedural distinction. In J. Cabreli Amaro, S. Flynn, \& J. Rothman (Eds.), Third language acquisition in adulthood (pp. 61-78). Philadelphia/ Amsterdam: John Benjamins. https://doi.org/10.1075/sibil.46.06bar

Bialystok, E. (2001). Metalinguistic aspects of bilingual processing. Annual Review of Applied Linguistics, 21, 168-181. https://doi.org/10.1017/S0267190501000101

Cenoz, J. (2001). The effect of linguistic distance, L2 status and age on crosslinguistic influence in third language acquisition. In J. Cenoz, B. Hufeisen, \& U. Jessner (Eds.), Crosslinguistic influence in third language acquisition (pp. 8-20). Clevedon: Multilingual Matters

De Angelis, G. (2007). Third or Additional Language Learning. Clevedon: Multilingual Matters.

Edwards, J. (1994). Multilingualism. London: Routledge. https://doi.org/10.4324/9780203430927

Faerch, C., \& Kasper, G. (1986). Cognitive dimensions of language transfer. In M. S. Sharwood \& E. Kellerman (Eds.), Crosslinguistic influence in second language acquisition (pp. 49-65). Oxford, UK: Pergamon Press.

Gogonas, N. (2009). Language Shift in Second-Generation Albanian Immigrants in Greece. Journal of Multilingual and Multicultural Development, 30(2), 95-110. https://doi.org/10.1080/01434630802307908

Hammarberg, B. (2001). Roles of L1 and L2 in L3 production and acquisition. In J. Cenoz, B. Hufeisen, \& U. Jessner (Eds.), Cross-linguistic influence in third language acquisition: Psycholinguistic perspectives (pp. 21-41). Clevedon: Multilingual Matters.

Herdina, P., \& Jessner, U. (2002). A Dynamic Model of Multilingualism: Perspectives of Change in Psycholinguistics. Clevedon: Multilingual Matters.

Hoffman, C. (2001). Towards a description of trilingual competence. International Journal of Bilingualism, 5, 1-17. https://doi.org/10.1177/13670069010050010101

Hoffmann, C., \& Stavans, A. (2007). The evolution of trilingual codeswitching from infancy to school age: The shaping of trilingual competence through dynamic language dominance. International Journal of Bilingualism, 11(1), 55-72. https://doi.org/10.1177/13670069070110010401

Kellerman, E. (1983). Now you see it, now you don't. In S. Gass \& I. Selinker (Eds.), Language transfer in language learning (pp. 112-134). Rowley, MA: Newbury House.

Lindqvist, C., \& Falk, Y. (2014). When Germans begin to learn Swedish. Which is the transfer source for function words, content words and syntax? EUROSLA Yearbook, 14, 225-239. https://doi.org/10.1075/eurosla.14.09lin

MacWhinney, B. (2000). The CHILDES project. Tools for analysing talk. London: Lawrence Erlbaum Associates.

Mayer, M. (1967). A boy, a dog and a frog. Dial Books for Young Readers. New York: Penguin Putnam Inc.

Murphy, S. (2003). Second language transfer during third language acquisition. Working Papers in TESOL \& Applied Linguistics, 3(2), 1-21.

Poulisse, N., \& Bongaerts, T. (1994). First language use in second language production. Applied Linguistics, 15(1), 36-57. https://doi.org/10.1093/applin/15.1.36

Ringbom, H. (1987). The role of first language in foreign language acquisition. Clevedon: Multilingual Matters.

Ringbom, H. (2001) Lexical Transfer in L3 Production. In J. Cenoz et al. (Eds.), Cross-linguistic Influence in Third Language Acquisition: Psycholinguistic Perspectives. Clevedon: Multilingual Matters.

Sjögren, Y. (2000). Multilingual conversations in Swedish. Ms.

Stedje, A. (1977). Tredjespråksinterferens i fritt tal—en jämförande studie (Third language interference in spontaneous speech - a comparative study). In R. Palmberg \& H. Ringbom (Eds.), Papers from the Conference on Contrasted Linguistics and Error Analysis (pp. 141-158). Åbo: ÅboAkademi. 


\section{Copyrights}

Copyright for this article is retained by the author(s), with first publication rights granted to the journal.

This is an open-access article distributed under the terms and conditions of the Creative Commons Attribution license (http://creativecommons.org/licenses/by/4.0/). 